\title{
What is the Role of the Geriatrician in Home Health Care?: An Overview Through an International Survey
}

\author{
(1) Birkan İlhan1, (1) Aslı Tufan2, (1) Büşra Can², (1) Gülistan Bahat33, (1) Mehmet Akif Karan³ \\ 1 University of Health Sciences Turkey, İstanbul Şişli Hamidiye Etfal Training and Research Hospital, Clinic of Internal Medicine, Division of \\ Geriatrics, Istanbul, Turkey \\ 2Marmara University Faculty of Medicine, Department of Internal Medicine, Division of Geriatrics, Istanbul, Turkey \\ 3istanbul University Faculty of Medicine, Department of Internal Medicine, Division of Geriatrics, Istanbul, Turkey
}

\begin{abstract}
Objective: To conduct an international survey among geriatricians on their current home care practice and opinions on the role of geriatricians in home care.

Materials and Methods: A survey consisting of 11 multiple-choice questions was administered to geriatricians from Turkey, Europe and the United States of America (USA) between January 2016 and March 2016. The survey included questions about the current practice of geriatricians in home care, Geriatric syndromes they observe in home care patients, opinions on whether the general practitioner should report the medical condition of home care patients to the geriatrician, what the geriatrician's role should be and components of the comprehensive assessment form which should be included in home health care. Answers were collected in a single center.

Results: Forty-three geriatricians from Turkey and 18 geriatricians from five different European countries and the USA participated in the survey. Forty-four percent $(n=27)$ stated that they currently offer visits to home care patients. Eighty-two percent $(n=50)$ of participants thought that geriatricians should provide consultations to home care patients and 44.3\% $(n=27)$ thought that geriatricians should visit patients directly.

Conclusion: Almost 45\% of geriatricians visit home care patients in their current practice. Nearly $85 \%$ of geriatricians thought that the general practitioner should report the medical condition of home care patients to the geriatrician, along with annual comprehensive geriatric assessment. Serving as a "consultant physician" was agreed upon by more than $80 \%$ of participants regarding the role of geriatricians in the practice of home care.
\end{abstract}

Keywords: Geriatrics, home health care, primary care, public health

\section{Introduction}

The population aged 65 years and over is increasing worldwide. The World Health Organization reports that 125 million people are aged 80 years or older (1), which has resulted in an increasing demand for healthcare services globally $(1,2)$. The population is aging in Turkey in a similar trend. Turkish Statistical Institute reports the proportion of the Turkish population aged 65 years and over has risen to $9.1 \%$ in 2019 (3). Caring for the growing number of elderly people and preventing disabilities are novel priorities both for the European Union and the Turkish Ministry of Health (4-6). Physical disability and frailty often increase with age, and cognitive disorders may trap the elderly in their home. Optimal home care can prevent undesirable outcomes including transition to intensive care or long-term care facilities (7). Consequently, social and healthcare services provided at home are becoming increasingly important.

Disparities are observed between countries regarding the role of the geriatrician in home care. Unfortunately, there is lack of data on the contribution of geriatricians to home care practice in Turkey. Understanding how geriatricians currently contribute

Address for Correspondence: Birkan İlhan, University of Health Sciences Turkey, İstanbul Şişli Hamidiye Etfal Training and Research Hospital, Clinic of Internal Medicine, Division of Geriatrics, İstanbul, Turkey

Phone: +90 2123735000 E-mail: birkanilhan@hotmail.com ORCID: orcid.org/0000-0001-6039-5866

Received: Jul 19, 2020 Accepted: Oct 06, 2020

Cite this article as: IIhan B, Tufan A, Can B, Bahat G, Karan MA. What is the Role of the Geriatrician in Home Health Care? : An Overview Through an International Survey. Eur J Geriatr Gerontol 2020;2(3):83-86

๑Copyright 2020 by the Academic Geriatrics Society / European Journal of Geriatrics and Gerontology published by Galenos Publishing House. 
to home care and their opinion on the issue might help improve home care services. In this study we surveyed geriatricians from Turkey, Europe and the United States of America (USA) to determine their role in home health care.

\section{Materials and Methods}

\section{Study Design and Survey Development}

A survey was developed based on the general guides of home care services and comprehensive geriatric assessment. The survey consisted of 11 multiple-choice questions about the current practice of geriatricians in home care, Geriatric syndromes they observe in home care patients; their opinions on whether the general practitioner (GP) should report the medical condition of home care patients to a geriatrician, what the role of a geriatrician should be and which components of the comprehensive assessment form should be included in home care practice. Some of the questions had multi select answer options (supplementary 1). Google Forms was used for online survey. The survey was administered to geriatricians from various cities in Turkey, Europe and the USA between January 2016-March 2016. Answers of the geriatricians who agreed to participate in the study were collected in a single center. Participants were able to answer the survey questions only once.

\section{Statistics}

The surveys were coded and scanned into a Google database. The proportions of answers to each question (with 95\% Cls) were calculated.

\section{Results}

Sixty-one geriatricians participated in the survey. Forty-three were geriatricians from Turkey, 15 from 8 different European countries (Austria, Belgium, Finland, Germany, The Netherlands, Portugal, Principality of Monaco, and Spain) and 3 from the USA. Twenty-seven of 61 (44.2\%) geriatricians stated that they offered visits to home care patients. Twenty-three (53.5\%) Turkish geriatricians and 4 (22.2\%) foreign geriatricians offered visits to home care patients. Among these 27 geriatricians, 92.6\% ( $n=25,19$ Turkish and 6 foreign) offered phone consultations, $74.1 \%(n=20 ; 15$ Turkish and 5 foreign) examined the patient in-person; $18.5 \%(n=5,2$ Turkish and 3 foreign) stated that they consult patients at the request of their GPs (Table 1). Among participants offering visits to home care patients, $17(40.5 \%)$ Turkish geriatricians visited 1 to 10 patients and 6 (14.3\%) Turkish geriatricians visited 11 to 50 patients (monthly). One (5.6\%) foreign geriatrician visited 1 to 10 patients and $2(11.2 \%)$ foreign geriatricians visited 11 to 50 patients (monthly).

The most frequent Geriatric syndromes they observed in home care patients were as follows: malnutrition (56\%), polypharmacy (51\%), urinary or fecal incontinence (49.2\%) and dementia (49.2\%). The participants stated that the comprehensive assessment form should include assessments of malnutrition (96.7\%), depression (90.2\%), polypharmacy (88.5\%), urinary incontinence (88.5\%) and falls/fear of falls (88.5\%) (Table 2). Eighty-four percent $(n=51,37$ Turkish and 14 foreign) of participants thought that the GP should report the medical condition of home care patients (along with annual Comprehensive Geriatric Assessment) to the geriatrician.

The question regarding the responsibility of the geriatrician in home care practice had multi select answer options. A total of $82 \%$ ( $n=50,35$ Turkish and 15 foreign) believed that geriatricians should provide consultation for home care patients while $44.3 \%$ ( $n=27,14$ Turkish and13 foreign) thought that geriatricians should provide direct patient care (Table 3).

\section{Discussion}

This international survey revealed that up to $45 \%$ of geriatricians currently offer visits to home care patients. Nearly $85 \%$ of geriatricians thought that the GP should report the medical condition of home care patients (along with annual

Table 1. Follow-up of home care patients by a total of 61 geriatricians

\begin{tabular}{|l|l|l|l|}
\hline \multicolumn{2}{|c|}{ Total } & \multicolumn{1}{l}{$\begin{array}{l}\text { Turkish } \\
\text { geriatricians }\end{array}$} & $\begin{array}{l}\text { Foreign } \\
\text { geriatricians }\end{array}$ \\
\hline & N (\%) & N (\%) & N (\%) \\
\hline $\begin{array}{l}\text { Phone call with the } \\
\text { care giver }\end{array}$ & $25(92.6)$ & $19(44.2)$ & $6(35.3)$ \\
\hline $\begin{array}{l}\text { Visit the patient in- } \\
\text { person }\end{array}$ & $20(74.1)$ & $15(34.9)$ & $5(29.4)$ \\
\hline $\begin{array}{l}\text { Consultation } \\
\text { requested by the GP }\end{array}$ & $5(18.5)$ & $2(4.7)$ & $3(17.6)$ \\
\hline GP: General practitioner & & \multicolumn{3}{l}{} \\
\hline
\end{tabular}

Table 2. Components of the comprehensive assessment form the participants thought shouldbe included in home care

\begin{tabular}{|l|l|}
\hline Malnutrition screening & $59(96.7)$ \\
\hline Depression screening & $55(90.2$ \\
\hline Questioning of polypharmacy & $54(88.5)$ \\
\hline Questioning of fecal/urinary incontinence & $54(88.5)$ \\
\hline Evaluating falls/fear of falling & $54(88.5)$ \\
\hline Pressure sore assessment & $53(86.9)$ \\
\hline Dementia screening & $53(86.9)$ \\
\hline Evaluating pain & $52(85.2)$ \\
\hline Evaluating hearing/sight & $52(85.2)$ \\
\hline Evaluating sleep & $51(83.6)$ \\
\hline Frailty criteria & $50(82)$ \\
\hline Vaccination state & $49(80.3)$ \\
\hline Evaluating sarcopenia & $33(54)$ \\
\hline
\end{tabular}




\begin{tabular}{|c|c|c|c|}
\hline \multicolumn{4}{|c|}{$\begin{array}{l}\text { Table 3. Opinions of } 61 \text { participants regarding therole } \\
\text { geriatrics in home care }\end{array}$} \\
\hline & Total & $\begin{array}{l}\text { Turkish } \\
\text { geriatricians }\end{array}$ & $\begin{array}{l}\text { Foreign } \\
\text { geriatricians }\end{array}$ \\
\hline & N (\%) & N (\%) & N (\%) \\
\hline $\begin{array}{l}\text { Should visit patients } \\
\text { directly }\end{array}$ & $27(44.3)$ & $14(33.3)$ & $13(72.2)$ \\
\hline $\begin{array}{l}\text { Should provide } \\
\text { consultations when } \\
\text { needed }\end{array}$ & $50(82)$ & 35 (83.3) & 15 (83.3) \\
\hline
\end{tabular}

Comprehensive Geriatric Assessment) to the geriatrician. Regarding the geriatrician's role in home care, more than $80 \%$ of participants stated that geriatricians should serve as "consultant physicians" for home care patients.

Practices in home health care for older adults have not been widely researched. A study from Istanbul/Turkey reported that $73 \%$ of calls for home care visits were requested by older adults (8). According to the study, although the demand was high, very few visits (13\% of total) were actually delivered to older adults and people with disabilities. The authors of the aforementioned study (8) stated that som e older adults demanded home visits even though they had no serious medical restrictions. They had repeat requests for difficulty in walking, joint pain or only psychological/emotional demands. Other reasons for the limited number of visits delivered were time constraints, biases involving the selection of patients and lack of training. Older adults mostly required home care services for "Geriatric syndromes" such as decreased functionality, chronic pain and depression, all of which need to be evaluated through "comprehensive geriatric assessment". Unmet treatment needs may have led older adults to call home services repetitiously. Hence, the contribution of a geriatrician might make a significant difference. A previous study held in China reported that services addressing the needs of dementia patients' and their caregivers were lacking in quality and quantity (9). Physicians in the rural areas were not confident in their skills for diagnosing and treating dementia. Another study concluded that geriatricians and GPs need to work in collaboration to provide the best possible home health care (10). However, from the GPs perspective, a consultant physician may not know the complete history as opposed to a GP's personal relationship with the patient (11). As the results of our survey indicate, patients may be consulted with a geriatrician on the GP's request and the GP may then orchestrate the patient's overall management.

We observed a difference between Turkish and foreign geriatricians in their answers to a few questions. Turkish geriatricians generally visited higher number of patients than foreign geriatricians. A higher number of foreign geriatricians, as compared to Turkish geriatricians, thought that geriatricians should visit the patients directly besides serving as a consultant
(72.2\% vs $33.3 \%$, respectively). This may be because the job description of physicians, health care systems, availability and public funding of home care services vary across countries (12).

It has been shown that geriatric intervention provides clinical benefits such as early discharge from hospital, costeffectiveness, reduced incidence of polypharmacy and reduced mortality (13-15). Geriatricians contribute greatly to the home health care of elderly with respect to quality of life, frailty and other Geriatric syndromes $(16,17)$. Older population is a significant user of health services, thus public health network has been reorganizing to adapt to the increasing demand for caring older adults $(4,5,18,19)$. Therefore, the contribution of geriatric assessment in home care practice is becoming ever more crucial. In the present study, participants mostly agreed that the contribution of geriatricians to home health care was necessary. Moreover, almost all participants agreed on evaluating Geriatric syndromes through comprehensive geriatric assessment. A higher prevalence of Geriatric syndromes such as dementia, urinary incontinence and malnutrition were reported in home care patients. Dementia, one of the major causes of disability among the elderly, often coexists with malnutrition. A reduction in energy intake, atrophy of brain regions which control appetite and energy balance, change in dietary habits and swallowing problems may account for this observation (20). Urinary incontinence is also a common problem in advanced dementia, making it one of the most frequently reported Geriatric syndromes in our survey.

Our study has some drawbacks and strengths. First of all, the number of foreign participants were slightly lower. In addition, as health care systems vary across countries, attitudes and practices of physicians related to home care may differ considerably. Thus, a larger study sample is needed to be able to generalize our results. As has been stated in a review on home care (21), studies that provide detailed information on the issue of home care, especially those comparing countries, are limited. To the best of our knowledge, the present study is the first in literature to question the role of geriatricians in home care practice. Further international studies which focus on the recommendations of geriatricians regarding home health care may help improve health care services for the elderly population worldwide.

\section{Conclusion}

Geriatricians in Turkey and abroad thought that the medical condition of home care patients should be reported to them and that they should serve as "consultant physicians".

\section{Acknowledgements}

We thank all of the participants who took time from their busy schedule to participate in this study. 


\section{Ethics}

Ethics Committee Approval: The study is a survey among physicians.

Informed Consent: The study is a survey among physicians.

Peer-review: Internally peer-reviewed.

\section{Authorship Contributions}

Design: B.I., A.T., B.C., G.B., M.A.K., Data Collection or Processing: A.T., Analysis or Interpretation: A.T., G.B., M.A.K., Literature Search: B.I., B.C., Writing: B.I., B.C.

Conflict of Interest: No conflict of interest was declared by the authors.

Financial Disclosure: The authors declared that this study received no financial support.

\section{References}

1. The World Health Organization. In: Ageing and Health.2018 Last Accessed Date: 07.07.2020. Available from: http://www.who.int/news-room/factsheets/detail/ageing-and-health

2. Rizzuto D, Melis RJF, Angleman S, Qiu C, Marengoni A. Effect of chronicdiseases and multimorbidity on survival and functioning in elderly adults.J Am Geriatr Soc 2017;65:1056-1060.

3. http://www.tuik.gov.tr/PreHaberBultenleri.do?id=33705 (Accessed July 7 2020)

4. Dubois CA, McKee M. Health and health care in the candidate countries to European Union: Common challenges, different circumstances, diverse policies. In Health policy and European Union enlargement. Mckee M, MacLehose L, Nolte E (eds). New York, USA:Open University Press;2004:48-54.

5. Gümüş R, Şahin A. Utilization of Health Services by the Elderly in Turkey between 2008 and 2012: analysis of Turkstat Health Surveys. DU Health Sci Inst 2016;6:74-78.

6. Turkish Ministry of Health, Report of the Home Care Services. 2016. Last Accessed Date: 07.07.2020. Available from: https://www.saglik.gov. $\mathrm{tr} / \mathrm{TR}, 11271 /$ saglik-bakanliginca-sunulan-evde-saglik-hizmetlerininuygulama-usul-ve-esaslari-hakkinda-yonerge.html

7. You E, Dunt DR, White V, Hoorn SV, Doyle C. Risk of death or hospital admission among community-dwelling older adults living with dementia in Australia. BMC Geriatrics 2014;14:71.

8. Hidiroglu $\mathrm{S}$, Kulbay $\mathrm{H}$, Karavus $\mathrm{M}$, Onsuz F. Expectations, requirements, and problems of family health care workers providing home services in Turkey. J Pak Med Assoc 2018;68:1696-1698.
9. Wu C, Gao L, Chen S, Dong H. Care services for elderly people with dementia in rural China: a case study. Bull World Health Organ 2016;94:167-173.

10. Dagneaux I, Gilard I, De Lepeleire J. Care of elderly people by the general practitioner and the geriatrician in Belgium: a qualitative study of their relationship. J Multidiscip Healthc 2012;5:17-25.

11. Bussche PV, Desmyter F, Duchesnes C, Massart V, Giet D, Petermans J, Vyncke V, Noortgate NVD, Willems S. Geriatric day hospital: opportunity or threat? A qualitative exploratory study of the referral behaviour of Belgian general practitioners. BMC Health Serv Res 2010;10:202.

12. Beerens $H C$, Sutcliffe $C$, Renom-Guiteras $A$, Soto $M E$, Suhonen $R$, Zabalegui A, Bökberg C, Saks K, Hamers JPH, RightTimePlaceCare Consortium. Quality of life and quality of care for people with dementia receiving long term institutional care or professional home care: the EuropeanRightTimePlaceCare study. J Am Med Dir Assoc 2014;15:54-61.

13. Parsons M, Parsons J, Rouse P, Pillai A, Mathieson S, Parsons R, Smith C, Kenealy T. Supported Discharge Teams for older people in hospital acute care: a randomised controlled trial. Age Ageing 2018;47:288-294.

14. Lea SC, Watts KL, Davis NA, Panayiotou B, Bankart MJ, Arora A, Chambers R. The potential clinical benefits of medicines optimisation through comprehensive geriatric assessment, carried out by secondary care geriatricians, in a general practice care setting in North Staffordshire, UK: a feasibility study. BMJ Open 2017;7:e015278. doi: 10.1136/ bmjopen-2016-015278.

15. Singh NA, Quine $S$, Clemson LM, Williams EJ, Williamson DA, Stavrinos TM, Grady JN, Perry TJ, Lloyd BD, Smith EU, Singh MA. Effects of high-intensity progressive resistance training and targeted multidisciplinary treatment of frailty on mortality and nursing home admissions after hip fracture: a randomized controlled trial. J Am Med Dir Assoc 2012;13:24-30.

16. Morris JN, Howard EP, Steel KR. Development of the interRAI home care frailty scale. BMC Geriat. 2016;16:188.

17. Foebel $A D$, van Hout $H P$, van der Roest $H G$, Topinkova $E$, Garms-Homolova V,Frijters $D$, Finne-Soveri $H$, Jónsson PV, Hirdes JP, Bernabei $R$, Onder G. Quality of care in European home care programs using the second generation interRAI Home Care Quality Indicators (HCOIs). BMC Geriatr 2015;15:148.

18. Pilger $\mathrm{C}$, Menon MU, Mathias TA. [Health services use among elderly people living in the community]. Rev Esc Enferm USP 2013;47:213-220.

19. Petermans J. The role of the geriatrician in the organization of the health care system. Rev Med Liege 2014;69:233-238.

20. Alzheimer's Disease International. Nutrition and dementia. Alzheimer's Disease International London: Alzheimer's Disease International;2014.

21. Genet N, Boerma WG, Kringos DS, Bouman A, Francke AL, Fagerström $C$ Melchiorre MG, Greco C, Devillé W. Home care in Europe: a systematic literature review. BMC Health Serv Res 2011;11:207. https://doi. org/10.1186/1472-6963-11-207. 